\title{
Üniversite Öğrencilerinin Yaşam Kalitesinin Değerlendirilmesi: Akdeniz Üniversitesi Örneği
}

DOI: $10.26466 /$ opus. 843021

$*$

\author{
Boran Toker * \\ * Doç. Dr., Akdeniz Üniversitesi, Serik İşletme Fakültesi, Serik ,Antalya/Türkiye \\ E-Posta: borantoker@akdeniz.edu.tr ORCID: 0000-0002-4658-1934 \\ ** Öğr. Gör. Dr., Akdeniz Üniversitesi, Manavgat MYO ,Antalya/Türkiye \\ E-Posta: bkalipci@gmail.com \\ ORCID: $\underline{0000-0001-7310-890 \mathrm{X}}$
}

\section{Öz}

Bu çalışmanın amacı, meslek yüksekokulunda öğrenim gören üniversite öğrencilerinde yaşam kalitesinin değerlendirilmesidir. Çalı̧̧ma nicel araştırma yönteminde desenlenmiştir. Veriler, Dünya Sağllk Örgütü Yaşam Kalitesi Ölçeği Kısaltılmış Versiyonu (WHOQOL-BREF) ve kişisel bilgi formu kullanılarak elde edilmiştir. Çalışmanın örneklemi, Akdeniz Üniversitesi'nin en çok öğrenci sayısına sahip meslek yüksekokullarından Manavgat Meslek Yüksekokulu'nda öğrenim gören 621 üniversite öğrencisinden oluşmaktadır. Verilerin normal dağılıma sahip olup olmadığııı saptamak için çarpıklık ve basıklık değgerleri incelenmiştir. Verilerin normal dağılıma sahip olduğu görülmüş ve analizlerde parametrik testlerden Pearson korelasyon analizi ve regresyon analizi kullanılmıştır. Korelasyon analizi sonucunda, hem genel yaşam kalitesi hem de genel sağlık durumu ile yaşam kalitesi boyutlarından fiziksel alan, psikolojik alan, sosyal alan ve çeoresel alan arasında pozitif yönde; ulusal alan ile negatif yönde ilişkiler olduğu görülmüştür. Regresyon analizi sonucunda ise yaşam kalitesi boyutlarnndan psikolojik alan ve çevresel alanın, öğrencilerin hem genel yaşam kalitesi hem de genel sağllk durumunu pozitif yönde; ulusal alan boyutunun ise negatif yönde etkilediği saptanmıştır. Bulgular mevcut literatür çerçevesinde tartışılmış ve okul yönetimleri için bazı önerilerde bulunulmuştur.

Anahtar Kelimeler: Yaşam kalitesi, üniversite öğrencileri, meslek yüksekokulu, WHOQOLBREF. 


\title{
Evaluation of the Quality of Life of University Students: Akdeniz University Case
}

\begin{abstract}
The aim of this study is to evaluate the quality of life of university students studying at a vocational school. The study was designed in quantitative research method. Data were obtained using the World Health Organization Quality of Life Questionaire Abbreviated Version (WHOQOL-BREF) and a personal information form. The sample of the study consisted of 621 university students studying at Manavgat Vocational School, one of the vocational schools of Akdeniz University with the highest number of students. The skewness and kurtosis values were examined to determine whether the data had a normal distribution. The data were found to have a normal distribution, and Pearson correlation analysis and regression analysis, which are among the parametric tests, were used in the analyses. As a result of the correlation analysis, it was observed that there were positive relationships between both overall quality of life and general health perceptions and the domains of quality of life, namely physical, psychological, social, environmental; and there was negative relationship with the national domain. As a result of the regression analysis, it was found that the psychological and environmental among the domains of quality of life positively affected both overall quality of life and general health perceptions of students; It was determined that the national dimension had a negative effect. The findings were discussed within the framework of the literature and some suggestions were made for school administrations.
\end{abstract}

Keywords: Quality of life, university students, vocational school, WHOQOL-BREF. 


\section{Giriş}

Yaşam kalitesi, farklı tanımlara sahip bir kavramdır ve mutluluk, başarı, zenginlik, sağlık ve memnuniyet gibi pozitif kavramlarla ilişkilendirilir. Ayrıca, bireylerin genel yaşam doyumunu, duygusal iyi oluşunu ve işlevselliğini etkileyen karmaşık bir yapıdır (Dučinskienè, Kalėdienė, ve Petrauskienè, 2003, s.76; Andre, Pierre ve McAndrew, 2017, s.1164). Bununla birlikte, yaşam kalitesi yeni bir kavram değildir, zira neyin iyilik veya mutluluğu oluşturduğuna dair tartışmalar Platon ve Aristoteles'e kadar uzanmaktadır. Yaşam kalitesi, mutluluk ve bir bütün olarak yaşamdan memnuniyet yönleri de dahil olmak üzere genel bir refah duygusu ifade eden popüler bir terimdir. Spesifik ve nesnel olmaktan çok geniş ve özneldir. Bununla birlikte son yıllarda, yaşam kalitesi kavramı, eğitim ve özel eğitim, sağlık hizmetleri (fiziksel ve davranışsal), sosyal hizmetler (engellilik ve yaşlanma) ve aileler alanlarındaki araştırma ve uygulamaların odak noktası haline gelmiştir (Schalock, Alonso ve Braddock, 2002, s.1; CDC, 2000, s.5).

Öte yandan üniversite eğitimi, öğrencilerin aile ve mevcut arkadaş çevresinden ayrılması, yeni insanlarla tanışarak farklı bir çevreye girmesi, yeni bilgiler edinme ve öğrenme sürecinde değişiklikler gibi birçok yenilik ve zorluğu beraberinde getirmektedir. $\mathrm{Bu}$ bağlamda üniversite öğrencilerinin yaşam koşulları, arkadaşlık ilişkileri ve sosyal hayatlarından beklentileri ile öğrenim gördükleri üniversitenin imkanları onların yaşam kalitelerine de önemli düzeyde etki etmektedir. Bunun sonucunda ise öğrencilerin yaşam kalitesi, onların dünya görüşlerini, geleceğe bakışlarını, başarılarını, okul ve hayatlarından memnuniyetlerini etkileyen önemli bir konu olarak karşımıza çıkmaktadır. Bu çalışmada, Dünya Sağlık Örgütü'nün (DSÖ) geliştirdiği ve üniversite öğrencilerinin yaşam kaliteleri ile ilişkilendirilebilecek önemli başlıkları içeren WHOQOL (The World Health Organization Quality of Life) ölçeğinin yaygın kısa formu aracılığı ile üniversite öğrencilerinin yaşam kalitesi düzeyleri incelenmiştir. Bu kapsamda çalışmanın amacı, meslek yüksekokulunda öğrenim görmekte olan üniversite öğrencilerinin yaşam kalitesi ile yaşam kalitesi boyutlarının karşlıklı ilişki ve etkilerinin tespit edilmesidir. Bu çalışma sonucunda elde edilen bulguların, üniversite yönetimlerine eğitim ve öğrencilerin yaşam kalitesinin iyileştirilmesi 
sürecinde katkı sağlayabilecek konuları açıklığa kavuşturması bakımından ayrı bir öneme sahip olduğu düşünülmektedir.

\section{Kavramsal Çerçeve}

Yaşam kalitesi, çeşitli bilimsel alanlar içerisinde gelişen karmaşık bir kavramdır. Bilimsel literatürde önerilen bazı tanımlar özellikle genel ifadeleri içermektedir. Bu kapsamda, toplumun ya da toplumsal refahın değerlendirilmesinden, bireylerin ya da grupların durumlarının özel olarak değerlendirilmesine kadar değişen genellik düzeylerinde yaklaşılabilen anlaşılması güç bir kavramdır. Yaşam kalitesinin operasyonel tanımları çeşitlilik göstermekte ve bu çeşitlilik sadece toplumsal veya bireysel bakış açıları ile değil, aynı zamanda uygulanabilir teorik modeller veya akademik yönelimlerle de desteklenmektedir (Pavlova, Vynogradskyi, Kurchaba ve Zikrach, 2017, s.1037; Ferrans ve Powers, 1985, s.15; Felce ve Perry, 1995, s.52). Bu çerçevede, yaşam kalitesi kavramı ile ilgili ortak bir fikir bulunmamakla beraber; bireyin yaşamının iyi gittiğine dair algıladığı fiziksel, işlevsel, ruhsal ve sosyal faktörlerin bileşiminden ortaya çıkan iyilik hali olarak tanımlanabilmektedir (Telatar ve Özcebe, 2004, s.163; Canbaz, Sünter, Dabak ve Pekşen, 2003, s.336). The WHOQOL Group (1996) yaşam kalitesini bireylerin yaşadığı kültür ve değerler sistemi bağlamında; "amaçları, beklentileri, standartları ve endişeleri açısından yaşamdaki konumlarını algılaması" olarak tanımlamaktadır. Yaşam kalitesi aynı zamanda, kişilerin fiziksel sağliklarından, psikolojik durumlarından, bağımsızlık seviyelerinden, sosyal ilişkilerinden ve çevrelerinin göze çarpan özellikleriyle ilişkilerinden karmaşık bir biçimde etkilenen geniş kapsamlı bir kavramdır. Ayrıca bu tanım, yaşam kalitesinin sosyal, kültürel ve çevresel bağlamda gömülü olan subjektif bir değerlendirmeye atıfta bulunduğu görüşünü yansıtmaktadır (World Health Organization, 1998, s.11). Böylece yaşam kalitesinin, bireyin kültürüne, değerlerine, hedeflerine, yaşam standartlarına, fiziksel ve çevresel şartlarına, ilişkilerine, dini ve manevi yönlerine uygun olarak yaşamdaki konumunu algılamasından oluştuğunu söyleyebiliriz (Macedo de Freitas vd., 2018, s. 2377).

DSÖ tarafından geliştirilen WHOQOL (The World Health Organization Quality of Life) ölçeği, üniversite öğrencilerinin yaşam 
kalitelerini geniş biçimde değerlendirilebilecek önemli başlıkları kapsamaktadır. Kültürlerarası olarak tasarlanan bu ölçek, değerlendirme süreci birçok ülkede yapılan araştırmalar sonucunda ortaya çıkmıştır. Ölçek içerisinde fiziksel, psikolojik, bağımsızlık, sosyalleşme, çevre ve kişisel inançlar olmak üzere altı temel boyut yer almaktadır (The WHOQOL Group, 1994, s.42-44; World Health Organization, 1998, s.1516):

İlk boyut olan fiziksel boyut bir kişinin yaşadığ 1 hoş olmayan fiziksel hisleri ve bu hislerin ne kadar rahatsız edici olabileceğini ve günlük yaşamı ne düzeyde etkilediğini incelemektedir. Bu bölüm içerisindeki sorular, kişinin ağrı üzerindeki kontrolünü ve ağrıdan kurtulma kolaylığını içermektedir. Bununla birlikte, enerji ve yorgunluk, cinsel aktivite, uyku ve dinlenme, algisal işlevler gibi alt boyutlardan oluştuğu görülmektedir.

Psikolojik boyut, bir insanın yaşamdaki pozitif duygulardan memnuniyetini, denge, barış, mutluluk, umutlu olma, sevinç ve iyi şeylerden ne kadar zevk aldığını inceler. Bir insanın geleceğe bakışı ve duyguları bu boyutun önemli bir parçası olarak kabul edilir. Birçok katılımcı için bu boyutun yaşam kalitesi ile eşanlamlı olduğu kabul edilebilir.

Bağımsızlık düzeyinin değerlendirildiği boyut, kişinin bir yerden bir yere gidebilmesi, evinin etrafında hareket edebilmesi, işyerinde dolaşabilmesi veya ulaşım hizmetlerine erişimi konusundaki görüşünü incelemektedir. Odak noktası, kişilerin, kullanılan araçlara bakılmaksızın, başkalarından yardım almaksızın gitmek istedikleri her yere gidebilme becerisidir. Bir kişinin hareketlilik için önemli ölçüde başka bir kişiye bağımlı olduğu her durumda, bunun yaşam kalitesini olumsuz etkileyeceği varsayılmaktadır.

Sosyalleşme boyutu, kişinin yaşamındaki yakın ilişki/lerde arzu edilen arkadaşlı̆̆ı, sevgiyi ve desteği ne ölçüde hissettiğini inceler. Bu boyut, kişinin sevme, sevilme ve başkalarıyla hem duygusal hem de fiziksel olarak yakın olma yeteneği ve fırsatını içerir.

Bir diğer boyut olan çevre, kişinin finansal kaynaklarının sağlıklı ve konforlu bir yaşam tarzı için ihtiyaçlarını nasıl karşıladığı konusundaki 
görüşünü inceler. Odak noktası, kişinin yaşam kalitesini etkileyebilecek neyi karşılayabileceği veya karşılayamayacağı üzerinedir.

Maneviyat, din ve kişisel inançların değerlendirildiği son boyut ise insanların kişisel inançlarının yaşam kalitelerini nasıl etkilediğini inceler. Örneğin, yaşamdaki zorluklarla başa çıkmalarına yardımcı olarak, deneyimlerini yapılandırarak, manevi ve kişisel sorulara anlam katmak ve daha genel olarak onlara bir refah duygusu sağlamak gibi. Bu bölüm, farklı dini inançlara (örneğin Budistler, Hıristiyanlar, Hindular, Müslümanlar) ve belirli bir dini yönelime uymayan kişisel ve manevi inançlara sahip kişilere hitap eder.

Üniversite, ergenlikten yetişkinliğe geçiş sürecidir. Üniversite öğrencilerinin bireysellik duygularını arayıp gerçekleştirdikleri, aynı zamanda başkalarıyla yakın ve sosyal ilişkiler arayarak kurdukları bir dönemdir (Özdemir ve Tuncay, 2008, s.1). Üniversite öğrencisi olmak ve üniversite hayatı hem ülkemizde hem de diğer ülkelerde endişe ve strese neden olabilecek bir ortam yaratmaktadır. Türkiye'de öğrenci hayatındaki en önemli adımlardan biri olan üniversite giriş sınavında başarılı olmak ise her yıl daha da zorlaşırken, bu zorluğun yanında ekonomik maliyeti de bir o kadar yüksek olmaktadır. Ancak, öğrenciler üniversite eğitimine başladıktan sonra, çoğunlukla üniversite yaşamı veya bölümleri ile ilgili beklentileri konusunda tatminsiz hissederler (Tümkaya, Aybek ve Çelik, 2008, s.2, Yıldırım, Kılıç ve Akyol, 2013, s.415). Bu çerçevede, üniversite öğrencilerinin yaşam kalitesi genel olarak, eğitim sistemi, ekonomik durum, aileden ayrı yaşama, sınav stresi, sosyal ilişkilerden kaynaklanan sorunlar ve yaşanılan ortam koşulları gibi faktörlerden etkilenmektedir (Özgür, Yıldırım ve Ziyaretli, 2008: s.59). Gençlikte en kritik dönemlerden biri, çocukluk ve yetişkinlik arasında bir köprü işlevi gören ve dinamik bir geçiş dönemi olarak bilinen üniversite yıllarıdır. Bu fiziksel, psikolojik, sosyal ve cinsel gelişim dönemindeki değişimlere ek olarak, üniversite öğrencileri yaşam tarzları üzerinde diğer ergenlerden daha fazla özerkliğe ve kontrole sahiptirler (Can vd., 2008, s.273, Lee ve Loke, 2005, s.209-210). Çünkü, yükseköğrenime başlamak, bu genç bireylere güven ve sorumluluk verir. Bu geçiş döneminde, genç birey kendi yaşamını kontrol etme ve geleceği hakkında etkili kararlar verme konusunda daha fazla sorumluluk üstlenir, bağımsız düşünme yeteneğini geliştirir ve sorunlarını çözme konusunda güven kazanır (Yıldırım vd., 2013, s.415). 
Bununla birlikte, evden uzak olmak, yeni bir gelişim aşamasına geçiş, akranlardan gelen baskı, akranlarla ve onların üniversite yaşamına ilişkin beklentileriyle çatışma, başarılarla ilgili hayal kırıklıkları, yeni bir sosyal ortamla başa çıkmada yaşanan sorunlar ve finansal zorluklar üniversite öğrencilerinin karşılaştığı yaygın stres faktörleridir (Hamaideh, 2011, s.69). Tüm bu sorunlar, öğrencilerin bir gruba ait olma, saygı ve sevgi görme, kimliklerini ve öz değerlerini tanıma gibi ihtiyaçlarını karşılamaları için bir tehdit oluşturmakta ve dolayısıyla öğrencilerin yaşam kalitesini de etkilemektedir (Yıldırım vd., 2013, s.415).

Çalışmanın bu bölümünde, ilgili literatürde WHOQOL ölçeği kullanılarak üniversite öğrencilerinin yaşam kalitesinin değerlendirildiği araştırmalar incelenmiştir. Burdurlu, Cabbar, Dagasan, Kulle, Ozenen ve Tomruk (2020) çalışmalarında Türkiye' de özel bir diş hekimliği okulunda öğrenim gören 281 öğrencinin yaşam kalitelerini değerlendirmişlerdir. Ilić vd. (2019) 760 tıp öğrencisi ile yaptıkları çalışmalarında, Sırp öğrenciler arasında WHOQOL-BREF ölçeğinin psikometrik özelliklerini değerlendirmişlerdir. Mendes-Rodrigues, Ranal ve Carvalho (2019) Brezilya'da 36 yüksek lisans öğrencisi ile yaptıkları çalışmalarında, öğrencilerin yaşam kalitesini WHOQOL-BREF ile değerlendirmişlerdir. Chandrasekaran vd. (2019) Malezya'da öğrenim gören 325 öğrenci ile tamamladıkları çalışmalarında, lisans öğrencileri arasında yaşam kalitesini ve düşük yaşam kalitesine neden olan faktörleri incelemişlerdir. Al-Shibani ve Al-Kattan (2019) WHOQOL-BREF'i kullanarak, Suudi Arabistan'daki 782 diş hekimliği öğrencisinin sağlığını ve yaşam kalitesini dört ana alana göre değerlendirmişlerdir. Cruz vd., (2018) ise 9 ülkeden (Şili, Mısır, Yunanistan, Hong Kong, Hindistan, Kenya, Umman, Suudi Arabistan ve ABD) 2012 hemşirelik öğrencisi ile yaptıkları kültürlerarası çalışmada, katılımcıların yaşam kalitesini ikamet ettikleri ülkeye göre ölçmeyi, karşılaştırmayı ve öğrencilerin yaşam kalitelerinin belirleyicilerinin ortaya çıkarmayı hedeflemişlerdir. Ali, Salam, Saeed, Sethi ve İrfan (2018) çalışmalarında, Pakistan'daki 883 tıp ve diş hekimliği öğrencisinin yaşam kalitelerini incelemişlerdir. Andre vd. (2017) de WHOQOL-BREF'i kullanarak ABD'de bir diş hekimliği okulundaki 384 öğrencinin yaşam kalitesini değerlendirmişlerdir. Moritz vd. (2016) Brezilya'daki bir devlet üniversitesindeki 95 hemşirelik öğrencisi ile yaptıkları çalışmalarında, lisans öğrencilerinin yaşam kalitesi düzeylerini 
analiz etmişlerdir. Heidari, Majdzadeh, Pasalar ve Nedjat (2014) ise İran'da Tahran Üniversitesinde öğrenim gören 242 tıp öğrencisi ile yaptıkları çalışmalarında, farklı eğitim seviyelerinde yaşam kalitesini incelemeyi ve bu kaliteye ilişkin en önemli faktörleri belirlemeyi amaçlamışlardır. Bampi, da Silva Baraldi, Guilhem, Pompeu ve de Oliveria Campos (2013) Brezilya'dan 56 lisans hemşirelik öğrencisi ile WHOQOL-BREF'i kullanarak yaptığı kesitsel çalışmada, öğrencilerin yaşam kalitesi algılarını saptamaya çalışmıştır. Vakili, Mohamad ve Vakili (2012) Malezya'nın Penang şehrinde yaşayan 35 İranlı ve 35 Malezyalı yüksek lisans öğrencisi ile yaptıkları çalışmalarında, öğrencilerin yaşam kalitesini WHOQOL-BREF ölçeği aracılığıyla değerlendirmişlerdir. Krägeloh vd. (2011) Yeni Zelanda'daki 274 tıp öğrencisi ile yaptıkları çalışmalarında, DSÖ Yaşam Kalitesi (WHOQOL-BREF) ölçeğinin kısaltılmış versiyonunun kullanımının doğrulanmasını amaçlamışlardır. Li, Kay ve Nokkaew (2009) ise 407 Taylandlı üniversite öğrencisi arasında yaşam kalitesini değerlendirmede WHOQOL-BREF'in Tayca versiyonunun performansını incelemişlerdir. Dučinskienè vd. (2003) Litvanya'daki 919 tıp fakültesi öğrencisi ile yaptıkları çalışmada, WHOQOL-BREF ölçeğini kullanarak üniversite öğrencileri arasındaki yaşam kalitesini değerlendirmişlerdir.

\section{Araştırmanın Hipotezleri}

Literatürden elde edilen bilgiler çerçevesinde oluşturulan ana ve alt hipotezler aşağıda yer almaktadır.

H1: Öğrencilerin yaşam kalitesi boyutlarından fiziksel alan (H1a), psikolojik alan $(\mathrm{H} 1 \mathrm{~b})$, sosyal alan $(\mathrm{H} 1 \mathrm{c})$, çevresel alan $(\mathrm{H} 1 \mathrm{~d})$, ulusal alan (H1e) ile genel yaşam kalitesi düzeyleri arasında pozitif yönde anlamlı bir ilişki vardır.

H2: Öğrencilerin yaşam kalitesi boyutlarından fiziksel alan (H2a), psikolojik alan $(\mathrm{H} 2 \mathrm{~b})$, sosyal alan $(\mathrm{H} 2 \mathrm{c})$, çevresel alan $(\mathrm{H} 2 \mathrm{~d})$, ulusal alan $(\mathrm{H} 2 \mathrm{e})$ ile genel sağlık durumu düzeyleri arasında pozitif yönde anlamlı bir ilişki vardır.

H3: Öğrencilerin yaşam kalitesi boyutlarından fiziksel alan (H3a), psikolojik alan (H3b), sosyal alan $\left(\mathrm{H}_{3} \mathrm{c}\right)$, çevresel alan $(\mathrm{H} 3 \mathrm{~d})$, ulusal alan (H3e) genel yaşam kalitesi düzeylerini pozitif yönde etkilemektedir. 
H4: Öğrencilerin yaşam kalitesi boyutlarından fiziksel alan (H4a), psikolojik alan (H4b), sosyal alan ( $\mathrm{H} 4 \mathrm{c})$, çevresel alan ( $\mathrm{H} 4 \mathrm{~d})$, ulusal alan $(\mathrm{H} 4$ e) genel sağlık durumu düzeylerini pozitif yönde etkilemektedir.

\section{Yöntem}

Bu çalışmanın amacı, meslek yüksekokulunda öğrenim gören üniversite öğrencilerinin yaşam kalitesi ile yaşam kalitesi boyutlarının ilişki ve etkilerinin analiz edilmesidir. Çalışmada, veri toplama aracı olarak anket yöntemi kullanılmıştır. Ankette, iki bölüm yer almaktadır. İlk bölümde öğrencilerin sosyo-demografik özelliklerini belirlemeye dönük sorulara yer verilmiştir. İkinci bölümde ise öğrencilerin yaşam kalitesi düzeylerinin ölçülmesi için DSÖ Yaşam Kalitesi Ölçeği Kısaltılmış Versiyonu (WHO Quality of Life Questionaire Abbreviated Version, WHOQOL-BREF) kullanılmıştır.

\section{Veri Toplama Aracı}

Çalışmada, öğrencilerin yaşam kalitesi düzeylerinin ölçülmesi için kullanılan DSÖ Yaşam Kalitesi Ölçeği Kısaltılmış Versiyonu (WHO Quality of Life Questionaire Abbreviated Version, WHOQOL-BREF), DSÖ Yaşam Kalitesi Değerlendirme Grubu (1994) tarafından geliştirilmiştir. Ölçekte "fiziksel alan, ruhsal alan, sosyal alan, çevresel alan ve ulusal alan" olmak üzere beş boyut ve genel yaşam kalitesi ile genel sağlık durumuna ilişkin sorularla birlikte toplam 27 soru bulunmaktadır. Ölçek 5'li likert tipindedir. DSÖ Yaşam Kalitesi Değerlendirme Grubu (1998) ölçeğin güvenirlik katsayısını (Cronbach alfa) "fiziksel alan" boyutu için 0,80; "ruhsal alan" boyutu için 0,76; "sosyal alan" boyutu için 0,66 ve "çevresel alan" boyutu için 0,80 olarak tespit etmiştir. Ölçek, Eser vd. (1999) tarafından Türkçe'ye çevrilerek geçerlilik ve güvenilirlik çalışmaları gerçekleştirilmiştir. Eser vd. (1999) ölçeğin güvenirlik katsayısını (Cronbach alfa) "fiziksel alan" boyutu için 0,83; "ruhsal alan" boyutu için 0,66; "sosyal alan" boyutu için 0,53 ve "çevresel alan" boyutu için 0,73 olarak rapor etmişlerdir. Kullanılan ölçek ekte yer almaktadır (Ek-1). 


\section{Evren ve Örneklem}

Veriler, Akdeniz Üniversitesi'ndeki en fazla öğrenciye sahip meslek yüksekokullarından bir olan Manavgat Meslek Yüksekokulu'ndan elde edilmiştir. Manavgat Meslek Yüksekokulu'nda 2018-2019 eğitim-öğretim yılı bahar döneminde aktif olarak 3690 öğrenci bulunduğu ve bu öğrencilerden de 1601'inin ders kaydı yaptırdığı saptanmıştır. Uygulama sırasında ilgili dönemde ders kaydı yaptıran 645 öğrenciye ulaşılabilmiş olup, bu sayıdan eksik cevap verenlerin çıarılmasından sonra toplam 621 öğrenciden elde edilen verilerle analizler yapılmıştır. Bu çerçevede, örneklemin evreni temsil etme oranı \% 38 (621/1601) olarak tespit edilmiş ve elde edilen bu rakam araştırma için yeterli düzeyde olduğu anlaşılmıştır (Gürbüz ve Şahin 2017, s.130).

\section{Katılımcı Profili}

Katılımcıların sosyo-demografik profiline ilişkin ayrıntılar Tablo 1'de yer almaktadır. Çalışmaya katılan öğrencilerin \%58,1'i erkek, $\% 41,9^{\prime} \mathrm{u}$ ise kadındır. Öğrencilerin \%58,4'ü 17-20 yaş, \%37,9'u 21-24 yaş ve geriye kalan \%3,7'si ise 25 yaş ve üzerindeki yaş aralığındadır. Öğrencilerin öğrenim gördükleri bölümlere bakıldığında; \%24,5'inin turizm ve otel işletmeciliği, \%15,6'sının bilgisayar programlama, \%14,3'ünün işletme, $\% 13,4$ 'ünün aşçllık, \%11,9'unun muhasebe ve vergi uygulamaları, $\% 10,8^{\prime}$ inin turizm ve seyahat hizmetleri, \%6'sının çocuk gelişimi ve \%3,5'inin ise pazarlama bölümünde olduğu görülmüştür. Bu bölümlerde öğrenim gören öğrencilerin $\% 62,5^{\prime} \mathrm{i}$ birinci sınıfta, $\% 37,5$ ' $\mathrm{i}$ ise ikinci sinıftadır. Öte yandan bu öğrencilerin \%76'sı birinci örgün öğretimde, $\% 24$ 'ü ise ikinci örgün öğretimdedir. Öğrencilerin aylık harcamaları incelendiğinde ise \%64,1'inin 1000 TL'ye kadar, \%20,8'inin 1001-1500 TL arası, \%8,4'ünün 1501-2000 TL aras1, \%3,1'inin 2001-2500 TL aras1 ve $\% 3,7$ 'sinin de $2501 \mathrm{TL}$ ve üzerinde olduğu görülmüştür. Bunun yanında, öğrencilerin çalışma durumuna bakıldığında ise \%62'si herhangi bir işte çalışmazken, \%38'i çalıştığını belirtmiştir. 
Tablo 1. Öğrencilerin sosyo-demografik profili

\begin{tabular}{|c|c|c|c|}
\hline & & Sayı / A.O. & $\%$ \\
\hline \multirow[t]{2}{*}{ Cinsiyet } & Erkek & 361 & 58,1 \\
\hline & Kadin & 260 & 41,9 \\
\hline \multirow[t]{3}{*}{ Yaş } & $17-20$ yaş arası & 362 & 58,4 \\
\hline & $21-24$ yaş arası & 235 & 37,9 \\
\hline & 25 yaş ve üzeri & 24 & 3,7 \\
\hline \multirow[t]{2}{*}{ Sinif } & Birinci sinıf & 388 & 62,5 \\
\hline & İkinci sınıf & 233 & 37,5 \\
\hline \multirow[t]{2}{*}{ Öğrenim Türü } & Birinci örgün öğretim & 472 & 76,0 \\
\hline & İkinci örgün öğretim & 149 & 24,0 \\
\hline \multirow[t]{8}{*}{ Bölüm } & Turizm ve otel işletmeciliği & 152 & 24,5 \\
\hline & Bilgisayar programlama & 97 & 15,6 \\
\hline & İşletme & 89 & 14,3 \\
\hline & Aşçlık & 83 & 13,4 \\
\hline & Muhasebe ve vergi uygulamaları & 74 & 11,9 \\
\hline & Turizm ve seyahat hizmetleri & 67 & 10,8 \\
\hline & Çocuk gelişimi & 37 & 6,0 \\
\hline & Pazarlama & 22 & 3,5 \\
\hline \multirow{6}{*}{$\begin{array}{l}\text { Aylı Harcama } \\
\text { Miktarı } \\
\text { (TL) }\end{array}$} & 500 TL'ye kadar & 132 & 21,3 \\
\hline & 501-1000 TL & 266 & 42,8 \\
\hline & 1001-1500 TL & 129 & 20,8 \\
\hline & 1501-2000 TL & 52 & 8,4 \\
\hline & 2001-2500 TL & 19 & 3,1 \\
\hline & 2501 TL ve üzeri & 23 & 3,7 \\
\hline \multirow[t]{2}{*}{ Çalışma durumu } & Evet & 236 & 38,00 \\
\hline & Hayır & 385 & 62,00 \\
\hline Yaş ortalaması & & $20,71 \pm 2,72$ & \\
\hline
\end{tabular}

\section{Verilerin Analizi}

Öğrencilerin verdiği cevaplar neticesinde toplanan veriler, SPSS 23.0 ve LISREL 8.54 istatistik paket programları ile analiz edilmiştir. İstatistiksel açıdan öncelikle ölçeğin güvenilirliği (Cronbach alfa) test edilmiştir. Sonrasında verilerin orjinal ölçekteki faktörlere olan uyumunu sınamak amacıyla doğrulayıcı faktör analizi (DFA) yapılmıştır ve modellerin değerlendirilmesinde sık bildirilen uyum indeksleri olan RMSEA, SRMR ve NFI değerleri kullanılmıştır (Hooper, Coughlan ve Mullen, 2008; McDonald ve Ho, 2002; Hu ve Bentler, 1999). Daha sonra verilerin normal dağılım gösterip göstermediğini saptamak için çarpıklık ve basıklık değerleri incelenmiştir. Tabachnick ve Fidell (2013) çarpıklık ve basıklık değerlerinin $(-1,5$ ile $+1,5)$ arasında olduğunda dağılımın normal 
olduğunun kabul edilebileceğini belirtmişlerdir. Bu çalışmada, çarpıklık ve basıklık değerleri $(-, 278$ ve,+ 952$)$ olarak saptanmıştır. Sonuç olarak, verilerin normal dağılım gösterdiği ve parametrik test koşullarına uygun olduğu anlaşılmıştır. Böylece çalışmanın ilk ve ikinci ana ve alt hipotezlerini test etmek amaciyla Pearson korelasyon analizi kullanılmıştır. Bunun yanında, çalışmadaki yaşam kalitesi boyutlarının birbirleri ile ilişkileri de yine Pearson korelasyon analizi ile değerlendirilmiştir. Çalışmanın üçüncü ve dördüncü ana ve alt hipotezlerini test etmek amaciyla da regresyon analizinden faydalanılmıştır.

\section{Bulgular}

Çalışmada kullanılan Yaşam Kalitesi ölçeğinin genel güvenilirlik değerinin (Cronbach alfa: 0,860) yüksek düzeyde olduğu saptanmıştır. Yaşam kalitesi ölçeğinin genel ve alt boyutlarının madde sayıları, ortalama, standart sapma ve güvenirlik değerleri Tablo 2'de yer almaktadır. Öğrencilerin yaşam kalitesi ölçeğinin genelinden 3,29 ortalamaya sahip olduğu tespit edilmiştir. Öğrencilerin yaşam kalitesi boyutları olan fiziksel alanın 3,15; psikolojik alanın 3,51; çevresel alanın 3,14 ; sosyal alanın 3,48 ve ulusal alanın ise 2,87 ortalamaya sahip olduğu görülmüştür.

Tablo 2. Yaşam kalitesi ölçeğinin madde sayıları, ortalama, standart sapma ve Cronbach alfa değerleri

\begin{tabular}{llll}
\hline Ölçekler & Madde sayısı & Ort \pm SS & Cronbach alfa \\
\hline Yaşam Kalitesi & 25 & $3,29 \pm 0,51$ & 0,860 \\
\hline Fiziksel & 7 & $3,15 \pm 0,57$ & 0,560 \\
\hline Psikolojik & 6 & $3,51 \pm 0,61$ & 0,606 \\
\hline Çevre & 8 & $3,14 \pm 0,63$ & 0,757 \\
\hline Sosyal & 3 & $3,48 \pm 0,85$ & 0,615 \\
\hline Ulusal & 1 & $2,87 \pm 1,12$ & - \\
\hline
\end{tabular}

Çalışma kapsamında ölçeğin doğrulayıcı faktör analizi uyum indekslerinin (SRMR=0,070; NFI=0,90; RMSEA=0,08) kabul edilebilir sinırlar içinde olduğu görülmüştür. 
Tablo 3'te yer alan Pearson korelasyon matrisine göre; yaşam kalitesi boyutu fiziksel alan ile genel yaşam kalitesi $(\mathrm{r}=0,294 ; \mathrm{p}<0,01)$ arasında istatiksel açıdan pozitif yönde anlamlı bir ilişki olduğu saptanmıştır. Sonuç olarak, H1a hipotezi kabul edilmiştir. Yaşam kalitesi boyutu psikolojik alan ile genel yaşam kalitesi $(\mathrm{r}=0,366 ; \mathrm{p}<0,01)$ arasında istatiksel açıdan pozitif yönde anlamlı bir ilişki olduğu saptanmıştır ve H1b hipotezi hipotezi kabul edilmiştir. Yaşam kalitesi boyutu sosyal alan ile genel yaşam kalitesi $(r=0,267 ; p<0,01)$ arasında istatiksel açıdan pozitif yönde anlamlı bir ilişki olduğu saptanmıştır. Sonuçta, H1c hipotezi hipotezi kabul edilmiştir. Yaşam kalitesi boyutu çevresel alan ile genel yaşam kalitesi $(\mathrm{r}=0,357 ; \mathrm{p}<0,01)$ arasında istatiksel açıdan pozitif yönde anlamlı bir ilişki olduğu saptanmıştır. H1d hipotezi hipotezi kabul edilmiştir. Yaşam kalitesi boyutu ulusal alan ile genel yaşam kalitesi $(r=-0,102$; $\mathrm{p}<0,05)$ arasında ise istatiksel açıdan pozitif yönde anlamlı bir ilişki olduğu saptanmıştır. H1e hipotezi de kabul edilmiştir.

Tablo 3'teki Pearson korelasyon matrisine göre; yaşam kalitesi boyutu fiziksel alan ile genel sağlık durumu $(r=0,233 ; \mathrm{p}<0,01)$ arasında istatiksel açıdan pozitif yönde anlamlı bir ilişki olduğu saptanmıştır. Sonuç olarak, $\mathrm{H} 2$ a hipotezi kabul edilmiştir. Yaşam kalitesi boyutu psikolojik alan ile genel sağlık durumu $(\mathrm{r}=0,348 ; \mathrm{p}<0,01)$ arasında istatiksel açıdan pozitif yönde anlamlı bir ilişki olduğu saptanmıştır ve $\mathrm{H} 2 \mathrm{~b}$ hipotezi hipotezi kabul edilmiştir. Yaşam kalitesi boyutu sosyal alan ile genel sağlık durumu $(\mathrm{r}=0,252 ; \mathrm{p}<0,01)$ arasında istatiksel açıdan pozitif yönde anlamlı bir ilişki olduğu saptanmıştır. Sonuçta, $\mathrm{H} 2$ c hipotezi hipotezi kabul edilmiştir. Yaşam kalitesi boyutu çevresel alan ile genel sağlık durumu $(\mathrm{r}=0,300 ; \mathrm{p}<0,01)$ arasında istatiksel açıdan pozitif yönde anlamlı bir ilişki olduğu saptanmıştır. $\mathrm{H} 2 \mathrm{~d}$ hipotezi hipotezi kabul edilmiştir. Yaşam kalitesi boyutu ulusal alan ile genel sağlık durumu $(r=-0,060 ; p<0,01)$ arasında ise istatiksel açıdan anlamlı bir ilişki saptanmamıştır. Dolayısıyla, H2e hipotezi reddedilmiştir.

Ayrıca, Tablo 3'teki Pearson korelasyon matrisinde yaşam kalitesi boyutları arasındaki ilişkiler incelendiğinde, fiziksel, psikolojik, sosyal ve çevresel alanların birbirleriyle anlamlı $(\mathrm{p}<0,01)$ ve pozitif yönde bir ilişki içerisinde olduğu saptanmıştır. Ulusal alan ile sadece çevresel alan arasında görece düşük düzeyli anlamlı $(\mathrm{p}<0,01)$, pozitif yönde bir ilişki bulunduğu da görülmüştür. 
Tablo 3. Korelasyon analizi sonuçları

\begin{tabular}{|c|c|c|c|c|c|c|c|c|}
\hline & & $\begin{array}{l}\text { Genel } \\
\text { Yaşam } \\
\text { Kalitesi }\end{array}$ & $\begin{array}{l}\text { Genel } \\
\text { Sağlık }\end{array}$ & $\begin{array}{l}\text { Fiziksel } \\
\text { Alan }\end{array}$ & $\begin{array}{l}\text { Psikolojik } \\
\text { Alan }\end{array}$ & $\begin{array}{l}\text { Sosyal } \\
\text { Alan }\end{array}$ & $\begin{array}{l}\text { Çevresel } \\
\text { Alan }\end{array}$ & $\begin{array}{l}\text { Ulusal } \\
\text { Alan }\end{array}$ \\
\hline Genel Yaşam & $\bar{r}$ & 1 & $351^{* *}$ & $294^{* *}$ & $366^{* *}$ & $267^{* *}$ & $357^{* *}$ &,$- 102^{*}$ \\
\hline Kalitesi & $\mathrm{p}$ & & ,000 & ,000 & ,000 & ,000 & ,000 & ,011 \\
\hline \multirow[t]{2}{*}{ Genel Sağlık } & $\mathrm{r}$ & & 1 & $233^{* *}$ & $348^{* *}$ & $252^{* *}$ & $300^{* *}$ &,- 060 \\
\hline & $\mathrm{p}$ & & & ,000 & ,000 & ,000 & ,000 & 133 \\
\hline \multirow[t]{2}{*}{ Fiziksel Alan } & $\mathrm{r}$ & & & 1 &, $581^{* *}$ &, $474^{* *}$ &, $542^{* *}$ & ,047 \\
\hline & $\mathrm{p}$ & & & & ,000 & ,000 & ,000 & ,246 \\
\hline \multirow[t]{2}{*}{ Psikolojik Alan } & $\mathrm{r}$ & & & & 1 &, $544^{* *}$ &, $568^{* *}$ &,- 011 \\
\hline & $\mathrm{p}$ & & & & & ,000 & ,000 & 781 \\
\hline \multirow[t]{2}{*}{ Sosyal Alan } & $\mathrm{r}$ & & & & & 1 &, $468^{* *}$ & ,017 \\
\hline & $\mathrm{p}$ & & & & & & ,000 & 669 \\
\hline \multirow[t]{2}{*}{ Çevresel Alan } & $\mathrm{r}$ & & & & & & 1 &, $115^{* *}$ \\
\hline & $\mathrm{p}$ & & & & & & & ,004 \\
\hline \multirow[t]{2}{*}{ Ulusal Alan } & $\mathrm{r}$ & & & & & & & 1 \\
\hline & $\mathrm{p}$ & & & & & & & \\
\hline
\end{tabular}

Regresyon analizinde, yaşam kalitesi boyutları olan" fiziksel, psikolojik, sosyal, çevresel ve ulusal alanlar" bağımsız değişkenler," genel yaşam kalitesi" sorusu ise bağımlı değişken olarak alınmıştır. Tablo 4'teki regresyon analizi sonuçlarına göre, yaşam kalitesi boyutlarından psikolojik alan ve çevresel alanın, genel yaşam kalitesini pozitif yönde; ulusal alanın ise negatif yönde etkilediği saptanmıştır. Yaşam kalitesinin boyutlarının genel yaşam kalitesindeki değişimi açıklama oranı \%18'dir (Düzeltilmiş $\mathrm{R}^{2}=0,179 ; \mathrm{p}<0,0001$ ). Genel yaşam kalitesi üzerinde en fazla etkiye sahip yaşam kalitesi boyutlarının ise sırasıyla; çevresel alan $(\beta=0,216 ; t=4,528 ; p<0,0001)$, psikolojik alan $(\beta=0,189 ; t=3,731 ; p<0,0001)$ ve ulusal alan $(\beta=-0,128 ; t=-3,477 ; p<0,0001)$ olduğu görülmüştür. Böylece, çalışmanın $\mathrm{H} 3 \mathrm{~d}$, $\mathrm{H} 3 \mathrm{~b}$ ve $\mathrm{H} 3$ e hipotezleri kabul edilmiştir. Sosyal alan $(\beta=0,040 ; \mathrm{t}=0,890 ; \mathrm{p}>0,05)$ ve fiziksel alan $(\beta=0,053 ; \mathrm{t}=1,117 ; \mathrm{p}>0,05)$ boyutlarında ise istatistiksel olarak anlamlı bir sonuca ulaşılamamıştır. Böylece çalışmanın $\mathrm{H} 3$ a ve $\mathrm{H} 3$ c hipotezleri reddedilmiştir. 
Tablo 4. Yaşam kalitesi boyutlarn ve genel yaşam kalitesi regresyon analizi sonuçlarn

\begin{tabular}{llllllll}
\hline & Beta & $\mathbf{T}$ & Sig. & $\mathbf{R}$ & $\mathbf{R}^{2}$ & $\begin{array}{l}\text { Düzeltilmiş } \\
\mathbf{R}^{2}\end{array}$ & $\mathbf{F}$ \\
\hline (Sabit) & & & & & & & \\
Fiziksel Alan &, 053 & 1,117 &, 260 & & & & \\
Psikolojik Alan &, 189 & 3,731 &, 000 & & & & \\
Sosyal Alan &, 040 &, 890 &, 374 & & & & 28,074 \\
Çevresel Alan &, 216 & 4,528 &, 000 &, 431 &, 186 &, 179 & \\
Ulusal Alan &,- 128 & $-3,477$ &, 001 & & & & \\
\hline
\end{tabular}

Bağımlı Değiş̧ken: Genel yaşam kalitesi

Diğer regresyon analizinde ise yaşam kalitesi boyutları olan" fiziksel, psikolojik, sosyal, çevresel ve ulusal alanlar" bağımsız değişkenler, "genel sağlık durumu" sorusu ise bağımlı değişken olarak alınmıştır. Regresyon analizi neticesinde, yaşam kalitesi boyutlarından psikolojik alan ve çevresel alanın genel sağlık durumunu pozitif yönde; ulusal alanın ise negatif yönde etkilediği saptanmıştır. Yaşam kalitesi boyutlarının genel sağlık durumunundaki değişimi açılama oranı \%14'tür (Düzeltilmiş $R^{2}=$ 0,138; $\mathrm{p}<0,0001)$. Genel sağlık durumu üzerinde en fazla etkiye sahip yaşam kalitesi alt boyutlarının ise sırasıyla; psikolojik alan $(\beta=0,234$; $t=$ 4,498; $p<0,0001)$, çevresel alan $(\beta=0,155 ; t=3,160 ; p<0,0001)$ ve ulusal alan $(\beta=-0,076 ; t=-2,015 ; p<0,0001)$ olduğu görülmüştür. Böylece, çalışmanın $\mathrm{H} 5 \mathrm{~b}, \mathrm{H} 4 \mathrm{~d}$ ve H4e hipotezleri kabul edilmiştir. Sosyal alan $(\beta=0,058 ; \mathrm{t}=$ 1,256; $\mathrm{p}<0,0001)$ ve fiziksel alan $(\beta=-0,010 ; \mathrm{t}=-0,208 ; \mathrm{p}<0,0001)$ boyutlarında ise istatistiksel olarak anlamlı bir sonuca ulaşılmamıştır. Dolayısıyla çalışmanın $\mathrm{H} 4$ c ve $\mathrm{H} 4$ a hipotezleri reddedilmiştir. Analiz neticesinde elde edilen bulgular Tablo 5'te yer almaktadır.

Tablo 5. Yaşam kalitesi boyutları ve genel sağlik durumu regresyon analizi sonuçları

\begin{tabular}{lccccccc}
\hline & Beta & $\mathbf{T}$ & Sig. & $\mathbf{R}$ & $\mathbf{R}^{2}$ & $\begin{array}{l}\text { Düzeltilmiş } \\
\mathbf{R}^{2}\end{array}$ & $\mathbf{F}$ \\
\hline (Sabit) & & 4,781 &, 000 & & & & \\
Fiziksel Alan &,- 010 &,- 208 &, 835 & & & & \\
Psikolojik Alan &, 234 & 4,498 &, 000 & & & & \\
Sosyal Alan &, 058 & 1,256 &, 210 & & & & \\
Çevresel Alan &, 155 & 3,160 &, 002 &, 380 &, 145 &, 138 & 2,789 \\
Ulusal Alan &,- 076 & $-2,015$ &, 044 & & & & \\
\hline
\end{tabular}

Bă̆ımlı Değıişken: Genel să̆lık durumu 


\section{Sonuç ve Tartışma}

Bu çalışmanın amacı, meslek yüksekokulunda öğrenim görmekte olan üniversite öğrencilerinin yaşam kalitesi ile yaşam kalitesi boyutlarının ilişki ve etkilerinin değerlendirilmesidir. Uygulama, Akdeniz Üniversitesi'nin en çok öğrenci sayısına sahip meslek yüksekokullarından biri olan Manavgat Meslek Yüksekokulu'ndaki öğrenciler üzerinde gerçekleştirilmiştir. Üniversite öğrencilerinin yaşam kalitesi ölçeğinin genelinden 3,29 ortalamaya sahip olduğu tespit edilmiştir. Öğrencilerin yaşam kalitesi boyutları olan fiziksel alanda 3,15; psikolojik alanda 3,51; çevresel alanda 3,14; sosyal alanda 3,48 ve ulusal alanda ise 2,87 ortalamaya sahip olduğu görülmüştür. Öğrencilerin yaşam kalitesi ölçeğinin genelinden ve fiziksel alan, psikolojik alan, çevresel alan ve sosyal alan boyutlarından aldıkları puanlar, ortalamanın üzerinde ve birbirine oldukça yakındır. Öte yandan, yaşam kalitesi boyutları içerisinde en yüksek ortalamaya psikolojik alan sahip iken; ulusal alan ise ortalamanın altında kalarak ölçekteki en düşük puana sahip boyut olmuştur. Heidari vd. (2014) ise çalışmalarında tıp öğrencilerinde psikolojik ve çevresel sağlık alanlarında ortalamalarının yüksek, fiziksel sağlık ve sosyal ilişki alanlarında ise düşük puan aldıklarını saptamışlardır. Öte yandan, Moritz vd. (2016) hemşirelik öğrencileri üzerinde yaptıkları çalışmalarında, yaşam kalitesi boyutları arasında, sosyal alanın en yüksek puana sahip olduğunu ve bunu psikolojik, çevresel ve fiziksel alanların izlediğini saptamışlardır. Cruz vd. (2018) ise farklı ülkelerden üniversite öğrencileri üzerinde gerçekleştirdikleri çalışmalarında, en yüksek puanın yaşam kalitesi boyutlarından fiziksel alanda, en düşük puanın ise sosyal alanda kaydedildiğini saptamışlardır. Çalışmalarında, algılanan en yüksek ve en düşük yaşam kalitesi boyutu ise ülkeler arasında farklılık göstermiştir. Ayrıca, Vakili vd. (2012) çalışmalarında, tüm lisansüstü öğrencileri için yaşam kalitesinin orta düzeyde (\%50-75) olduğunu saptamışlardır. Burdurlu vd. (2020) ise diş hekimliği öğrencilerinin genel yaşam kalitesinin iyi olarak derecelendirildiğini ve öğrencilerin psikolojik alanda en düşük ve fiziksel alanda ise en yüksek puanlara sahip olduklarını tespit etmişlerdir. Bampi vd. (2013) de hemşirelik lisans öğrencilerinde psikolojik ve çevre alanlarının sırasıyla en iyi ve en kötü puanlar olduğunu belirtmişlerdir. 
Çalışmada yapılan korelasyon analizi neticesinde, genel yaşam kalitesi ile yaşam kalitesinin alt boyutlarından fiziksel alan, psikolojik alan, sosyal alan ve çevresel alan arasında pozitif yönde, ulusal alan ile negatif yönde anlamlı ilişkiler olduğu görülmüştür. Benzer şekilde, genel sağlik durumu ile yaşam kalitesinin alt boyutlarından fiziksel alan, psikolojik alan, sosyal alan ve çevresel alan arasında pozitif yönde, ulusal alan ile negatif yönde anlamlı ilişkiler olduğu görülmüştür. Ayrıca, çalışmada yer alan yaşam kalitesi boyutları arasındaki ilişkiler de incelenmiştir. Fiziksel, psikolojik, sosyal ve çevresel alanların birbirleriyle pozitif bir ilişki içerisinde olduğu saptanmıştır. Ulusal alan ile yalnızca çevresel alan arasında görece düşük düzeyli, pozitif bir ilişki bulunduğu da görülmüştür.

Benzer şekilde, Ilić vd. (2019) tıp öğrencileri ile yaptıkları çalışmalarında, tüm yaşam kalitesi alan puanlarının, genel yaşam kalitesi alg1sı ve genel sağlık algısı puanları ile güçlü bir korelasyon gösterdiğini belirtmişlerdir. Andre vd. (2017) de diş hekimliği öğrencilerinde, dört boyut ve genel yaşam kalitesi ve genel sağlık memnuniyeti ile ilgili iki bağımsız soru arasındaki korelasyon katsayılarının 0,39 ile 0,64 arasında değiştiğini ve farkların istatistiksel olarak anlamlı olduğunu ifade etmişlerdir. Krägeloh vd. (2011) de tıp öğrencileriyle gerçekleştirdikleri çalışmalarında, yaşam kalitesi ölçeğinin tüm boyutlarının, genel yaşam kalitesi ve genel sağlık durumları ile ilişkili olduğunu saptamışlardır. Li vd. (2009) ise üniversite öğrencileri ile yaptıkları çalışmalarında, sosyal ilişki alanı dışındaki üç alan puanının da genel yaşam kalitesi veya genel sağlık durumu ile anlamlı ilişkilere sahip olduğunu ortaya koymuşlardır. Yine benzer şekilde, Al-Shibani ve Al-Kattan (2019) diş hekimliği öğrencileri üzerindeki çalışmalarında dört alan ile genel yaşam kalitesi ve genel sağlıkla ilgili memnuniyete ilişkin iki bağımsız soru arasındaki korelasyonların 0.245 ile 0.542 arasında değiştiğini ve farklılıkların da istatistiksel olarak anlamlı olduğunu belirtmişlerdir. Bunun yanında, Chandrasekaran vd. (2019) ise lisans öğrencileri üzerinde gerçekleştirdikleri çalışmalarında, psikolojik ile fiziksel alan puanları arasında ve çevre ile fiziksel alanla ilgili yaşam kalitesi arasında güçlü pozitif ilişkiler tespit etmişlerdir. Dučinskienẻ vd. (2003) de çalışmalarında, tıp öğrencilerinde fiziksel ve çevresel alanlar ile sosyal ve psikolojik alanlar arasında güçlü korelasyonlar bulmuşlardır. MendesRodrigues vd. (2019) yüksek lisans programı öğrencileri ile yaptıkları 
çalışmalarında, yine benzer şekilde fiziksel alan ile psikolojik ve sosyal ilişkiler; psikolojik alan ile sosyal ilişkiler ve sosyal ilişkiler ile çevre alanları arasında pozitif korelasyon olduğunu tespit etmişlerdir.

Çalışmadaki regresyon analizi sonuçlarına göre, yaşam kalitesi boyutları olan psikolojik alan ve çevresel alanın, öğrencilerin genel yaşam kalitesini pozitif yönde etkilediği saptanmıştır. Yaşam kalitesinin ulusal alan boyutu ise genel yaşam kalitesini negatif yönde etkilemektedir. Yaşam kalitesinin bu boyutlarının genel yaşam kalitesindeki değişimi açıklama oranı \%18 olarak tespit edilmiştir. Genel yaşam kalitesi üzerinde en fazla etkiye sahip yaşam kalitesi boyutları ise sırasıyla; çevresel alan, psikolojik alan ve ulusal alandır. Çalışmanın ikinci regresyon analizi neticesinde ise yaşam kalitesi boyutları olan psikolojik alan ve çevresel alanın öğrencilerin genel sağlık durumunu pozitif yönde etkilediği görülmüştür. Yaşam kalitesinin ulusal alan boyutunun ise genel sağlık durumunu negatif yönde etkilediği saptanmıştır. Yaşam kalitesinin bu boyutlarının genel sağlık durumunundaki değişimi açıklama oranının \%14 olduğu tespit edilmiştir. Genel sağlık durumu üzerinde en fazla etkiye sahip yaşam kalitesi boyutlarının ise sırasıyla; psikolojik alan, çevresel alan ve ulusal alan olduğu görülmüştür. Benzer olarak, Li vd. (2009) de fiziksel, psikolojik ve çevresel alanların genel yaşam kalitesi üzerinde önemli öngörücü etkileri olduğunu ve bu regresyon modelinin belirleme katsayısının $\left(\mathrm{R}^{2}\right)$ ise 0,34 olarak tespit edildiğini ifade etmişlerdir. Öte yandan, yalnızca fiziksel ve psikolojik alanların genel sağlık durumu üzerinde önemli ölçüde öngörücü etkilere sahip olduğunu ve bu regresyon modelinin belirleme katsayısının $\left(R^{2}\right)$ ise 0,30 olarak ortaya çıktığını da belirtmişlerdir. Ayrıca, sosyal alan dışındaki üç alanın tümünün, genel yaşam kalitesi ve genel sağlık kombinasyonunu önemli ölçüde tahmin ettiğini de saptamışlardır.

Üniversite öğrencisi gençlerin yaşam kalitesi, onların hayata bakışlarını, gelecek beklentilerini, başarılarını, okullarından ve yaşamlarından memnuniyetlerini etkilemesinin yanında topluma daha faydalı bireyler olmalarını da etkileyen önemli unsurlardan biridir. Bu açıdan yaklaşıldı̆̆ında, üniversite yönetimlerinin öğrencilerin yaşam kalitelerinin artırılmasına dönük stratejiler geliştirmesi gerektiği söylenebilir. Bu çerçevede, üniversitelerde öğrencilerin yaşam kalitesini artıracak çevresel anlamda iyileştirici önlemler alabilmek için kampüs 
ortamının fiziki koşullarının iyileştirilmesi yanında ulaşım imkanlarının artırılması da sağlanabilir. Bununla birlikte, öğrencilerin sağlık hizmetlerinden daha hızlı ve etkin biçimde faydalanabilmesi sayesinde fiziksel ve psikolojik sağlıklarını koruyabilmeleri de mümkün olabilecektir. Ayrıca öğrencilerin psikolojik sağlıklarına ve sosyal ilişkilerine destek olmak adına onlara verilen rehberlik ve psikolojik danışmanlık hizmetleri geliştirilmeli ve bu hizmetlerden öğrencilerin rahat bir şekilde, çok fazla prosedürlerle uğraşmadan faydalanabilmesi sağlanmalıdır. Bu çerçevede üniversite yönetimleri, öğrenciler üzerinde düzenli aralıklarla yapacakları genel yaşam kalitesi ve üniversite yaşamı kalitesine dönük araştırmalarla onların yaşam kalitesi ve dolayısıyla başarı ve mutluluklarının artırılmasında etkili olan unsurları tespit ederek iyileştirici önlemler de alabilirler. Çünkü yaşam kalitesi yüksek olan gençler daha mutlu, daha başarılı, hayata sıkı sıkıya sarılan, geleceğe umutla bakan ve dolayısıyla topluma da fayda sağlayan bireyler olacaklardır.

Bunun yanında, çalışmanın bazı kısıtları da bulunmaktadır. Araştırma bulgularının öz-bildirime dayalı ve kesitsel olması çalışmadaki önemli kısıtlardan biridir. Çalışmanın diğer bir kısıtı ise örneklem grubunu yalnızca üniversite öğrencilerinin oluşturmasıdır. Bütün bu nedenlerle, ileride yapılacak çalışmaların meslek yüksekokulu öğrencileri haricinde, lise, fakülte ve lisansüstü öğrencileri ve farklı sosyoekonomik düzeylerdeki, çalışan gençler üzerinde yapılması önerilebilir. Bununla birlikte, gelecekte yapılacak çalışmalarda öğrencilerin gelecek beklentileri, kişilik özellikleri, başarı durumları, mutluluk düzeyleri gibi değişkenler ile yaşam kaliteleri arasındaki ilişkiler ve etkiler de incelenebilir. 


\title{
EXTENDED ABSTRACT
}

\section{Evaluation of the Quality of Life of University Students: Akdeniz University Case}

\author{
Boran Toker -Mehmet Bahadır Kalıpçı \\ Akdeniz University- Akdeniz University
}

Quality of life is a concept with different definitions and is associated with positive concepts such as happiness, success, wealth, health, and satisfaction. In addition, it is a complex structure that affects the overall life satisfaction, emotional well-being and functionality of individuals (Dučinskienė, Kalèdienè, \& Petrauskienè, 2003, p.76; Andre, Pierre, \& McAndrew, 2017, p.1164). It is a popular term that refers to a general sense of well-being, including aspects of happiness, and satisfaction with life as a whole. It is broad and subjective rather than specific and objective. However, in recent years, the concept of quality of life has become the focus of research and practice in the fields of education and special education, health services (physical and behavioral), social services (disability and aging), and families (Schalock, Alonso, \& Braddock, 2002, p.1; CDC, 2000, p.5).

The WHOQOL Group (1996) defined the quality of life as individuals' perceptions of their position in life in the context of the culture and value systems in which they live and in relation to their goals, expectations, standards, and concerns. Quality of life is also a comprehensive concept incorporating in a complex way the persons' physical health, psychological state, level of independence, social relationships, personal beliefs, and their relationships to salient features of the environment (World Health Organization, 1998, p.11).

The WHOQOL (The World Health Organization Quality of Life) scale developed by WHO covers important topics that can broadly evaluate the quality of life of university students. This scale, which is designed as crosscultural, has emerged as a result of researches conducted in many countries. There are six basic domains in the scale: Physical, psychological, level of independence, social relationships, environment, and personal 
beliefs (The WHOQOL Group, 1994, p.42; World Health Organization, 1998, p.15).

The aim of this study is to analyze the relationship and effects of quality of life and quality of life dimensions of university students studying at vocational school. Questionnaire method was used as data collection tool in the study. There are two parts in the survey. In the first part, questions about determining the socio-demographic characteristics of the students were included. In the second part, the WHO Quality of Life Questionaire Abbreviated Version (WHOQOL-BREF) was used to measure the quality of life of the students.

The sample of the study consisted of 621 university students studying at Manavgat Vocational School, one of the vocational schools of Akdeniz University with the highest number of students. First, reliability of the scale (Cronbach's alpha) was tested statistically. Then, confirmatory factor analysis (CFA) was performed to test the fit of the data to the factors in the original scale. Pearson correlation analysis and regression analysis were used to test the hypotheses of the research.

As a result of the correlation analysis, it was observed that there were positive relationships between both overall quality of life and general health perceptions and the domains of quality of life, namely physical, psychological, social, environmental; and there was negative relationship with the national domain.

According to the results of the regression analysis, it was determined that the psychological domain and the environmental domain, which are the dimensions of quality of life, positively affect the overall quality of life of the students. The national domain dimension of the quality of life negatively affects the overall quality of life. It was determined that these dimensions of quality of life explained the change in overall quality of life as $18 \%$. The dimensions of quality of life that have the most impact on the overall quality of life are respectively; environmental domain, psychological domain and national domain.

As a result of the second regression analysis, it was seen that the psychological domain and the environmental domain, which are the dimensions of quality of life, positively affect the general health perceptions of the students. It was determined that the national domain dimension of the quality of life negatively affected the general health 
perceptions. It was determined that these dimensions of quality of life explained the change in general health perceptions as $14 \%$. The dimensions of the quality of life that have the most impact on the general health perceptions are respectively; psychological domain, environmental domain, and national domain.

The quality of life of university students is one of the important factors that affect their outlook on life, future expectations, success, satisfaction with school and life, as well as their becoming more useful individuals to society. From this point of view, it can be said that university administrations should develop strategies to increase the quality of life of students.

\section{Kaynakça / References}

Ali, O., Salam, Z., Saeed, T., Sethi, M. R. ve Irfan, M. (2018). Quality of life of medical and dental students of Peshawar. Journal of Postgraduate Medical Institute (Peshawar-Pakistan), 32(2), 188-193.

Al-Shibani, N. ve Al-Kattan, R. (2019). Evaluation of quality of life among dental students using WHOQOL-BREF questionnaire in Saudi Arabia: A cross sectional study. Pakistan Journal of Medical Sciences, 35(3), 668.

Andre, A., Pierre, G. C. ve McAndrew, M. (2017). Quality of life among dental students: a survey study. Journal of Dental Education, 81(10), 11641170.

Bampi, L. N. da Silva, Baraldi, S., Guilhem, D., Pompeu, R. B. ve de Oliveira Campos, A. C. (2013). Nursing undergraduate students' perception of quality of life. Nursing, 34(1), 125-132.

Burdurlu, M. C., Cabbar, F., Dagasan, V., Kulle, C., Ozenen, D. O. ve Tomruk, C. O. (2020). Assessing the Quality of Life of Dental Students by using the WHOQOL-BREF Scale. Balkan Journal of Dental Medicine, 24(2), 9195.

Can, G., Ozdilli, K., Erol, O., Unsar, S., Tulek, Z., Savaser, S., ve Durna, Z. (2008). Comparison of the health-promoting lifestyles of nursing and non-nursing students in Istanbul, Turkey. NursingEHealth Sciences, 10(4), 273-280. 
Canbaz, S., Sünter, A. T., Dabak, S. ve Pekşen, Y. (2003). The prevalence of chronic diseases and quality of life in elderly people in Samsun. Turkish Journal of Medical Sciences, 33(5), 335-340.

Centers for Disease Control and Prevention - CDC (2000). Measuring Healthy Days. Atlanta, Georgia: USA.

Chandrasekaran, S. K., Jacob, L., Ling, J. L. S., Rajendran, A., John, C. D. C., Jian, A. T. Z., ... ve Chi, L. E. (2019). Quality of life among undergraduate students in Ipoh, Perak: A cross-sectional study using WHOQOL-BREF. Quest International Journal of Medical and Health Sciences, 2(2), 16-22.

Cruz, J. P., Felicilda-Reynaldo, R. F. D., Lam, S. C., Contreras, F. A. M., Cecily, H. S. J., Papathanasiou, I. V., ve Colet, P. C. (2018). Quality of life of nursing students from nine countries: A cross-sectional study. Nurse Education Today, 66, 135-142.

Dučinskienè, D., Kalėdienė, R. ve Petrauskienė, J. (2003). Quality of life among Lithuanian university students. Acta med Lituan, 10(2), 76-81.

Eser, E., Fidaner, H., Fidaner, C., Eser, S. Y., Elbi, H. ve Göker, E. (1999). WHOQOL-100 ve WHOQOL-BREF'in psikometrik özellikleri. Psikiyatri Psikoloji Psikofarmakoloji (3P) Dergisi, 7(2), 23-40.

Felce, D. ve Perry, J. (1995). Quality of life: Its definition and measurement. Research in Developmental Disabilities, 16(1), 51-74.

Ferrans, C. E. ve Powers, M. J. (1985). Quality of life index: development and psychometric properties. Advances in Nursing Science. 8(1), 15-24.

Gürbüz, S. ve Şahin, F. (2017). Sosyal Bilimlerde Araştırma Yöntemleri FelsefeYöntem-Analiz. Ankara: Seçkin Yayıncılık.

Hamaideh, S. H. (2011). Stressors and reactions to stressors among university students. International Journal of Social Psychiatry, 57(1), 69-80.

Heidari, M., Majdzadeh, R., Pasalar, P. ve Nedjat, S. (2014). Quality of life of medical students in Tehran University of Medical Sciences. Acta Medica Iranica, 52(5), 390-399.

Hooper, D., Coughlan, J. ve Mullen, M. R. (2008). Structural equation modelling: Guidelines for determining model fit. Electronic journal of Business Research Methods, 6(1), 53-60.

Hu, L. T. ve Bentler, P. M. (1999). Cutoff criteria for fit indexes in covariance structure analysis: Conventional criteria versus new alternatives. Structural Equation Modeling: A Multidisciplinary Journal, 6(1), 1-55. 
Ilić, I., Šipetić-Grujičić, S., Grujičić, J., Živanović Mačužić, I., Kocić, S. ve Ilić, M. (2019). Psychometric properties of the world health organization's quality of life (WHOQOL-BREF) questionnaire in medical students. Medicina, 55(12), 772.

Krägeloh, C. U., Henning, M., Hawken, S. J., Zhao, Y., Shepherd, D. ve Billington, R. (2011). Validation of the WHOQOL-BREF quality of life questionnaire for use with medical students. Educ Health (Abingdon), 24(2), 545.

Lee, R. L. ve Loke, A. J. Y. (2005). Health-promoting behaviors and psychosocial well-being of university students in Hong Kong. Public Health Nursing, 22(3), 209-220.

Li, K., Kay, N. S. ve Nokkaew, N. (2009). The performance of the World Health Organization's WHOQOL-BREF in assessing the quality of life of Thai college students. Social Indicators Research, 90(3), 489-501.

Macedo de Freitas, A. C., de Miranda Malheiros, R. M., da Silva Lourenço, B., Fernandes Pinto, F., Cruz de Souza, C. ve Lopes Almeida, A. C. (2018). Intervening factors in the quality of life of nursing student. Journal of Nursing UFPE/Revista de Enfermagem UFPE, 12(9), 2376-2384.

McDonald, R. P., ve Ho, M. H. R. (2002). Principles and practice in reporting structural equation analyses. Psychological Methods, 7(1), 64-82.

Mendes-Rodrigues, C., Ranal, M. A. ve Carvalho, D. V. (2019). Postgraduate Students: An Alert about Quality of Life. World Journal of Education, 9(1), 135-144.

Moritz, A. R., Marques-Pereira, E., Pereira-de-Borba, K., Clapis, M. J., Gryczak-Gevert, V. ve Mantovani, M. D. F. (2016). Quality of life of undergraduate nursing students at a Brazilian public university. Investigacion y Educacion en Enfermeria, 34(3), 564-572.

Özdemir, U. ve Tuncay, T. (2008). Correlates of loneliness among university students. Child and Adolescent Psychiatry and Mental Health, 2(1), 29.

Özgür, G., Yıldırım, S. ve Ziyaretli, G. (2008). Hemşirelik öğrencilerinin yaşam kalitesi konusundaki görüşleri ve yaşam doyumları. Ege Üniversitesi Hemşirelik Fakültesi Dergisi, 24(1), 57-65.

Pavlova, I., Vynogradskyi, B., Kurchaba, T. ve Zikrach, D. (2017). Influence of leisure-time physical activity on quality of life of Ukrainian students. Journal of Physical Education and Sport, 17(3), 1037-1042. 
Schalock, R. Alonso, M. A. V. ve Braddock, D. L. (2002). Handbook on Quality of Life for Human Service Practitioners. Washington: American Association on Mental Retardation.

Tabachnick, B. G. ve Fidell, L. S. (2013). Using multivariate statistics: International edition. Boston: Pearson Education Limited.

Telatar, T. G. ve Özcebe, H. (2004). Yaşlı nüfus ve yaşam kalitelerinin yükseltilmesi. Türk Geriatri Dergisi, 7(3), 162-165.

The WHOQOL Group (1994). Development of the WHOQOL: Rationale and current status. International Journal of Mental Health, 23(3), 24-56.

The WHOQOL Group (1996). Introduction, administration, scoring and generic version of the assessment, field trial version. World Health Organization: Geneva.

The WHOQOL Group (1998). The World Health Organization quality of life assessment (WHOQOL): development and general psychometric properties. Social Science \& Medicine, 46(12), 1569-1585.

Tümkaya, S., Aybek, B. ve Çelik, M. (2008). An investigation of students' life satisfaction and loneliness level in a sample of Turkish students. Journal of Human Sciences, 5(1), 1-15.

Vakili, Z., Mohamad, A. R. ve Vakili, M. A. (2012). A quantitative study of quality of life (QOL) on postgraduate students in Universiti Sains Malaysia. Caspian Journal of Applied Sciences Research, 1(7), 28-32.

World Health Organization. (1998). Programme on mental health: WHOQOL user manual (No. WHO/HIS/HSI Rev. 2012.03). World Health Organization.

Yıldırım, Y., Kılıç, S. P. ve Akyol, A. D. (2013). Relationship between life satisfaction and quality of life in Turkish nursing school students. Nursing \& Health Sciences, 15(4), 415-422.

\section{Ek-1:}

1. Yaşam kalitenizi nasıl buluyorsunuz?

2. Sağlı̆̆ınızdan ne kadar hoşnutsunuz?

3. Ağrılarınızın yapmanız gerekenleri ne kadar engellediğini düşünüyorsunuz?

4. Günlük uğraşlarınızı yürütebilmek için herhangi bir tıbbi tedaviye ne kadar ihtiyaç duyuyorsunuz?

5. Yaşamaktan ne kadar keyif alırsınız?

6. Yaşamınızı ne ölçüde anlamlı buluyorsunuz?

7. Dikkatinizi toplamada ne kadar başarılısınız?

8. Günlük yaşamınızda kendinizi ne kadar güvende hissediyorsunuz? 
9. Fiziksel çevreniz ne ölçüde sağlıklıdır?

10. Günlük yaşamı sürdürmeniz için yeterli gücünüz kuvvetiniz var mı?

11. Bedensel görünüşünüzü kabullenir misiniz?

12. İhtiyaçlarınızı karşılamaya yeterli paranız var mı?

13. Günlük yaşantınızda size gerekli bilgi ve haberlere ne ölçüde ulaşabiliyorsunuz?

14. Boş zamanları değerlendirme uğraşları için ne ölçüde fırsatınız var?

15. Bedensel hareketlilik (etrafta dolaşabilme, bir yerlere gidebilme) beceriniz nasıldir?

16. Uykunuzdan ne kadar hoşnutsunuz?

17. Günlük uğraşlarınızı yürütebilme becerinizden ne kadar hoşnutsunuz?

18. İş görme kapasitenizden ne kadar hoşnutsunuz?

19. Kendinizden ne kadar hoşnutsunuz?

20. Aileniz dışındaki kişilerle ilişkilerinizden ne kadar hoşnutsunuz?

21. Cinsel yaşamınızdan ne kadar hoşnutsunuz?

22. Arkadaşlarınızın desteğinden ne kadar hoşnutsunuz?

23. Yaşadığınız yerin koşullarından ne kadar hoşnutsunuz?

24. Sağlık hizmetlerine ulaşma koşullarınızdan ne kadar hoşnutsunuz?

25. Ulaşım olanaklarınızdan ne kadar hoşnutsunuz?

26. Ne sıklıkta hüzün, ümitsizlik, bulantı, çökkünlük gibi olumsuz duygulara kapilırsinız?

27. Yaşamınızda size yakın kişilerle (sevgili, eş, iş arkadaşı, akraba) ilişkilerinizde baskı ve kontrolle ilgili zorluklarınız ne ölçüdedir?

\section{Kaynakça Bilgisi / Citation Information}

Toker, B. ve Kalıpçı, M. B. (2021). Üniversite öğrencilerinin yaşam kalitesinin değerlendirilmesi: Akdeniz Üniversitesi örneği. OPUS-Uluslararası Toplum Araştırmaları Dergisi, 18(39), 405-430. DOI: $10.26466 /$ opus.843021. 